http://jmscr.igmpublication.org/home/ ISSN (e)-2347-176x ISSN (p) 2455-0450

crossref DOI: https://dx.doi.org/10.18535/jmscr/v9i7.01

\title{
Role of GGT in diagnosis of metabolic syndrome: A clinic-based cross- sectional survey in M.P.
}

Authors

\section{Laxminarayan Meena ${ }^{1 *}$, Shreya Nigoskar ${ }^{2}$, Randhir Kumar Pandey ${ }^{3}$, Vandana Mahapatra 4}

${ }^{1,3}$ Department of Biochemistry, ${ }^{2}$ Department of Biochemistry, ${ }^{4}$ Department of Physiotherapy

${ }^{1,3}$ National Institute of Medical Sciences and Research, Jaipur, Rajasthan

${ }^{2}$ Index Medical College, Indore, M.P.

${ }^{4}$ NIMS College of Physiotherapy, Jaipur, Rajasthan

*Corresponding Author

\section{Dr Laxminarayan Meena}

Sr. Demonstrator, Department of Biochemistry, National Institute of Medical Sciences \& Research, Jaipur, Rajasthan, India

Abstract
Background \& Objectives: The aim of this study is to know if the liver function tests (LFT), particularly gamma
glutamyl transferase (GGT), have a analytical value in diagnosis of metabolic syndrome (MS).
Methods: A cross-sectional, single-center study was carried out with 500 subjects. While other 250 were sex and
age matched healthy control subjects. Blood pressure, liver function tests, fasting blood glucose levels and lipid
profile of the subjects were recorded.
Results: The denote values of alanine amino transferase (ALT), aspartate aminotransferase (AST) and GGT levels
were statistically significantly superior in MS group. The denote values of liver enzymes, for female/ male subjects
in MS group, AST; ALT and GGT respectively. When the sample is divided into quartiles of the GGT levels,
increase in GGT is positively correlated with increased MS prevalence. In ROC analysis GGT is as strongly
associated with the IDF diagnostic components as is each individual IDF component, except elevated systolic
blood pressure. In covariance analysis, there was significant relationship between elevated GGT levels and MS
presence after adjustment for age, sex and MS diagnostic criteria; but not AST and ALT levels. In multivariance
analysis, in MS group, a high GGT was positively associated with CVD prevalance compared to low GGT group
independent of age, sex and smoking habits.
Interpretation \& Conclusion: Eminent liver enzymes, though in normal ranges, particularly at higher quartiles,
play a middle part in early diagnosis of fat overflow to the liver. Concerning the accessibility and ease of these
tests in routine clinical practice, they, particularly GGT, have potential to be considered in algorithms for
metabolic syndrome.
Keywords: Gamma Glutamyl Transferase (GGT), Alanine Amino Transferase (ALT), Aspartate Aminotransferase
(AST).

\section{Introduction}

Metabolic disease, also known as disease $\mathrm{X}$, is linked with elevated danger for the expansion of cardiovascular syndrome (CVD). Since its occurrence is rising global, a large compact of concentration has been aimed at to this disease, in the past more than a few years ${ }^{[1,2]}$. After the classification of the relationship of metabolic disease with improved cardiovascular syndrome risk, the analysis of metabolic disease has gained 
more significance. Now characterization of MS, ATP III or International Diabetes Federation (IDF) criteria, contain increased waist border, raised triglycerides, low HDL, raised fasting glucose and raised blood pressure (BP), are in use ${ }^{[3,4]}$. While not well defined, other experimental and biochemical markers connected with MS are known.

Non-alcoholic fatty liver disease (NAFLD), accounting for asymptomatic increase of aminotransferase levels in up to 90 per cent of cases, is the most frequent cause of irregular liver function tests results ${ }^{[5-8]}$.

G-Glutamyl Transferase (GGT) is shown to be an independent risk factor for the mortality and morbidity of cardiovascular diseases in recent epidemiological and clinical studies10. In addition, several prospective studies reported that baseline serum GGT concentration was an independent risk factor for the development of coronary artery disease (CAD), diabetes mellitus, stroke and hypertension $^{[9,10]}$.

Raise liver enzymes, as moderately susceptible and easily obtain markers of NAFLD, replicate chronic ectopic fat statement in the liver that may be helpful in MS diagnosis. With respect to our clinical explanation, we hypothesize that high liver function tests, specially GGT levels, are linked with common metabolic syndrome and in this distinguishing they may have a analytical significance in diagnosis of metabolic syndrome. To test this hypothesis we analyzed liver function tests (ALT, AST and GGT), blood pressure, fasting blood glucose levels and lipid profile, body mass index, and waist perimeter of subjects not including any known hypertension, diabetes mellitus, impaired fasting glucose and hyperlipidemia. By this way, we aimed to show the importance of liver function tests, especially GGT, in diagnosis of metabolic syndrome ${ }^{[11,12]}$.

\section{Materials and Methods}

A cross-sectional, single-center study was carried out between October 2019 and June 2020, in Index Hospital, with 500 subjects who were admitted to our Internal Medicine, Gastroenterology and Endocrinology outpatient clinic not including any known hypertension, diabetes mellitus, impair fasting glucose and hyperlipidemia. 250 subjects were diagnosed with MS with IDF criteria; while other 250 were healthy control subjects.

The study was approved by the Index Medical College Ethics Committee and informed consent was obtained from patients.

\section{Statistical Methods}

We assess the relationship of the standard analytical mechanism for MS with LFTs. ROC analysis is used to determine the optimum value of variables in terms of their sensitivity and specificity for predicting MS. The univariate association between CVD status and the presence or absence of raised LFTs and MS and other factors was examined using the Chi-squared test, Student's t-test and the Chi-squared test of trend. Covariance study was performed to see the relationship of liver function tests and MS.

\section{Results}

Table: 1 Biological and clinical characteristics of the study population

\begin{tabular}{|c|c|c|}
\hline & MS $(n=250)$ & Control $(n=250)$ \\
\hline Age $( \pm$ SD $)$ & $52.3(3.4)$ & $49.1(2.9)^{*}$ \\
\hline $\mathrm{F} / \mathrm{M}(\%)$ & $140 / 110(56)$ & $160 / 90(64)^{*}$ \\
\hline BMI $\left(\mathrm{kg} / \mathrm{m}^{2}\right)( \pm \mathrm{SD})$ & $31.9(5)$ & $27.2(5.1)^{*}$ \\
\hline $\mathrm{HDL}(\mathrm{mg} / \mathrm{dl})( \pm \mathrm{SD})$ & $41.1(8.7)$ & $53.2(7.6)^{*}$ \\
\hline LDL $(\mathrm{mg} / \mathrm{dl})( \pm \mathrm{SD})$ & $132.1(9.9)$ & $114.4(6.6)^{*}$ \\
\hline $\begin{array}{l}\text { Triglyceride }(\mathrm{mg} / \mathrm{dl}) \\
( \pm \mathrm{SD})\end{array}$ & $274.5(26.7)$ & $113.7(10.1)^{*}$ \\
\hline $\begin{array}{l}\text { Systolic BP }(\mathrm{mm} \mathrm{Hg}) \\
( \pm \text { SD })\end{array}$ & $139.2(12.7)$ & $117.1(9.5)^{*}$ \\
\hline $\begin{array}{l}\text { Diastolic BP }(\mathrm{mm} \\
\mathrm{Hg})( \pm \mathrm{SD})\end{array}$ & $87.7(8.2)$ & $75.5(4.7)^{*}$ \\
\hline $\mathrm{AST}(\mathrm{U} / \mathrm{l})( \pm \mathrm{SD})$ & $22.1(10.1)$ & $16.7(5.3)^{*}$ \\
\hline $\operatorname{ALT}(\mathrm{U} / \mathrm{l})( \pm \mathrm{SD})$ & $27.8(10.3)$ & $18.2(3.5)^{*}$ \\
\hline GGT (U/l) $( \pm \mathrm{SD})$ & $41.9(11.2)$ & $20(6.1)^{*}$ \\
\hline Current smoker n (\%) & $24(4.7)$ & $28(4.8)^{*}$ \\
\hline Dyslipidemia (\%) & $164(37.8)$ & $26(4.7)^{*}$ \\
\hline $\operatorname{DMn}(\%)$ & $37(9.1)$ & $0(0.0)^{*}$ \\
\hline IGT n $(\%)$ & $79(18.6)$ & $3(0.7)^{*}$ \\
\hline HT n $(\%)$ & 139(32.2) & $15(2.4)^{*}$ \\
\hline CVD n (\%) & $65(15.4)$ & $18(3.0)^{*}$ \\
\hline
\end{tabular}

F/M, female/male; BMI, body mass index; BP, blood pressure; DM, diabetes mellitus; IGT, impaired glucose tolerance; HT, hypertension; CVD, cardiovascular disease. $* P$ value $<0.05$ 
The major biological and clinical characteristics of the study population $(n=500)$ separated between patients with $(n=250)$ or without $(n=250)$ metabolic syndrome are presented in Table-1.

Seventeen percent of on the whole patients were diagnosed with hypertension and 21 percent were with dyslipidemia, 4 percent with diabetes mellitus and 9 with impaired glucose tolerance. The indicate body mass index value (BMI) was superior in MS group than controls, but the distinction was not statistically significant.

We also compared the liver function tests between subjects with or without each component of MS. In this sub criteria analysis, there was no significant difference of age between subjects with or without dyslipidemia and abdominal obesity. However, there was considerable variation of age between subjects with or without hypertension, diabetes mellitus and impaired glucose tolerance. The highest mean values of liver enzymes has been found in abdominal obesity group $(\mathrm{ALT}=31.6 \mathrm{U} / \mathrm{l} ; \mathrm{AST}=25.0 \mathrm{U} / 1$; GGT $=42.8 \mathrm{U} / \mathrm{l})$. Only GGT levels were significantly higher in subjects with dyslipidemia than subjects without.

The mean values of liver enzymes, for female/ male subjects in control group, AST; ALT and GGT respectively, were; 17.8/20.4 U/1; 18.3/23.4 $\mathrm{U} / 1 ; 19.2 / 26.7 \mathrm{U} / \mathrm{l}$. There were statistically significant differences between genders in liver enzymes in control group. In MS group, the mean value of these enzymes respectively were; 21.5/20.7 U/l; 26.9/29.5 U/l; 36.9/43.1 U/l and there was statistically significant difference between genders only in GGT levels but not in AST and ALT levels in MS group.

\section{Discussion}

In our study, transaminases are in normal ranges in 92.2 percent and GGT are in normal ranges in 82.4 per cent of MS patients. In particular ALT and GGT values are considerably elevated than manage group but still remain in normal ranges. In a study of Balogun et al on 90 patients with type 2 diabetes and 90 non diabetic controls the ALT and
GGT values were significantly higher (53.9 IU/1 and $25.3 \mathrm{U} / 1$ respectively) in the diabetic group compared to the controls (35.4 IU/1 and 9.2 IU/1 respectively). Moreover, the most predominant LFT abnormality in diabetic group was found to be isolated elevation of GGT ${ }^{[13]}$.

\section{Conclusion}

Prominent liver enzymes, while in normal ranges, particularly at higher quartiles, participate a middle role in early analysis of fat excess to the liver. Moreover, GGT may cooperate a role in early analysis of metabolic syndrome with a high prognostic value for both metabolic syndrome and cardiovascular infection presence. Concerning the availability and ease of these tests in routine clinical practice and their universal consistency, these answer point to the possible of liver enzymes, particularly GGT, to be measured in algorithms for metabolic syndrome.

\section{References}

1. Grundy SM, Brewer HB Jr, Cleeman JI, Smith SC Jr, Lenfant 1. C. Definition of metabolic syndrome: report of the National Heart, Lung, and Blood Institute/American Heart Association conference on scientific issues related to definition. Circulation 2004; 109 : 433-8.

2. Lorenzo C, Okoloise M, Williams K, Stern MP, Haffner SM. 2. The metabolic syndrome as predictor of type 2 diabetes: the San Antonio Heart Study. Diabetes Care 2003; $26: 3153-9$.

3. Alberti KG, Zimmet P, Shaw J, IDF Epidemiology Task Force 3. Consensus Group : The metabolic syndrome: a new worldwide definition. Lancet 2005; 366 : 1059-62.

4. Expert panel on detection, evaluation and treatment of 4. high blood cholesterol in adults (Adult Treatment Panel III). Executive summary of the third report of the National Cholesterol 
5. Clark JM, Brancati FL, Diehl AM. The prevalence and etiology 5. of elevated aminotransferase levels in the United States. Am J Gastroenterol 2003; 98 : 9607.

6. Seppälä-Lindroos A, Vehkavaara $S$, Häkkinen AM, Goto T, 6. Westerbacka J, Sovijärvi A, et al. Fat accumulation in the liver is associated with defects in insulin suppression of glucose production and serum free fatty acids independent of obesity in normal men. J Clin Endocrinol Metab 2002; 87 : 3023-8.

7. Gupte P, Amarapurkar D, Agal S, Baijal R, Kulshrestha P, 7. Pramanik S, et al. Non-alcoholic steatohepatitis in type 2 diabetes mellitus. J Gastroenterol Hepatol 2004; 19 : 854-8.

8. Falck-Ytter Y, Younossi ZM, Marchesini G, McCullough AJ. 8. Clinical features and natural history of nonalcoholic steatosis syndromes. Semin Liver Dis 2001; 21 : 17-26.

9. Ruhl CE, Everhart JE. Epidemiology of nonalcoholic fatty 9. liver. Clin Liver Dis 2004; $8: 501-19$, vii.

10. Ruttmann E, Brant LJ, Concin H, Diem G, Rapp K, Ulmer 10. H, Vorarlberg Health Monitoring and Promotion Program Study Group. Gammaglutamyltransferase as a risk factor for cardiovascular disease mortality: an epidemiological investigation in a cohort of 163,944 Austrian adults. Circulation 2005; 112 : 2130-7.

11. Lee DH, Jacobs DR Jr, Gross M, Kiefe CI, Roseman J, 11. Lewis CE, et al. Gammaglutamyltransferase is a predictor of incident diabetes and hypertension: the Coronary Artery Risk Development in Young Adults (CARDIA) Study. Clin Chem 2003; 49 : 1358-66.
12. Jousilahti P, Rastenyte D, Tuomilehto J. Serum g-glutamyl 12. transferase, selfreported alcohol drinking, and the risk of stroke. Stroke 2000; 31 : 1851-5.

13. Balogun W18. O, Adeleye JO, Akinlade KS, Adedapo KS, Kuti M. Frequent occurrence of high gamma-glutamyl transferase and alanine amino transferase among Nigerian patients with type 2 diabetes. Afr J Med Med Sci 2008; 37 : 177-83. 